\title{
Microwave Irradiation Assisted Preparation of Chitosan Composite Microsphere for Dye Adsorption
}

\author{
Xiaoyu Chen and Lindun He \\ School of Material Engineering, Jinling Institute of Technology, Nanjing 211169, China \\ Correspondence should be addressed to Xiaoyu Chen; chxy@jit.edu.cn
}

Received 14 September 2016; Revised 30 November 2016; Accepted 18 December 2016; Published 2 January 2017

Academic Editor: Bernabé L. Rivas

Copyright ( 2017 X. Chen and L. He. This is an open access article distributed under the Creative Commons Attribution License, which permits unrestricted use, distribution, and reproduction in any medium, provided the original work is properly cited.

\begin{abstract}
Chitosan-activated carbon composite microspheres were prepared by emulsion cross-linking method and its adsorption properties for methyl orange were studied. Chitosan solution was mixed with activated carbon powder and then chitosan was cross-linked by epichlorohydrin under microwave irradiation. SEM photos show that the composite microspheres have diameters of $200-400 \mu \mathrm{m}$ and activated carbon powder dispersed on the surface of composite microsphere. FTIR spectrum indicates chitosan is successfully cross-linked. Microwave irradiation can effectively shorten the cross-linking time. Composite microspheres have enhanced dye adsorption capacity for methyl orange compared to chitosan microspheres. Kinetic studies showed that the adsorption followed a pseudo-second-order model. Isotherm studies show that the isotherm adsorption equilibrium is better described by Freundlich isotherm. Regeneration results show that adsorption capacity of composite microsphere decreased about $5.51 \%$ after being reused for three times. These results indicated that chitosan-activated carbon composite microsphere has potential application in the removal of dye from wastewaters.
\end{abstract}

\section{Introduction}

Dyes are widely used in industries such as textiles, leather, and paper. As a result, considerable amounts of colored wastewater are generated $[1,2]$. Dyes in wastewater are harmful to environment due to their toxicity and difficulty of degradation.

Conventional methods of removing dyes from wastewater include adsorption, coagulation and flocculation, chemical oxidation, ozonation, activated sludge, electrochemical techniques, ion exchange, and membrane filtration [3-5]. Adsorption is a promising method to remove dyes from wastewater [6-8] because of its low cost and easy technical access [9]. In addition, adsorption can remove trace amounts of dye molecules in water compared to the conventional methods [10].

Active carbon powder, an amorphous carbon material with high specific surface [11], is a widely used adsorbent for the removal of various pollutants because of its low cost and high adsorption capacity [12]. However, used as adsorbent to remove dye from wastewater, activated carbon powder is difficult to be separated from wastewater and is difficult with regard to regeneration after adsorption [13]. To solve this shortage, people use complex of activated carbon to prepare composite [3].

Chitosan is biodegradable and nontoxic biopolymer which is composed of $\beta$-D-glucosamine and acetyl- $\beta$-Dglucosamine residues with a 1,4 linkage [14]. Chitosan is used to adsorb various kinds of dyes especially anionic dye due to the amino groups of chitosan [15]. Chitosanactivated carbon composite has been used for heavy metal adsorption from water [12]. But a chitosan-activated carbon composite microsphere used for dye adsorption has never been reported.

Chitosan is usually cross-linked to avoid dissolution in acidic solutions and to fabricate microspheres [16]. In this study, chitosan was complex with activated carbon powder and then cross-linked under microwave irradiation. The structure and adsorption properties of microsphere for methyl orange were investigated. 


\section{Materials and Methods}

2.1. Agent and Facility. Chitosan was supplied by Shanghai Lanji Science and Technology company (degree of deacetylation) > 90\%; activated carbon was supplied by Liyang Zhuxi Activated Carbon company; span 80 was supplied by Sinopharm Chemical Reagent Co., Ltd.; acetic acid, liquid paraffin, formaldehyde, $\mathrm{NaOH}$, epichlorohydrin, ethanol, and methyl orange are all analytically pure.

2.2. Preparation of Composite Microsphere. Chitosan-activated carbon composite microsphere was prepared by emulsion cross-linking method. $2 \mathrm{~g}$ chitosan was dissolved in $2 \%$ acetic acid and then activated carbon powder was added and was agitated to dispersion. The mass ratios of chitosan/activated carbon are $10: 1,10: 2,10: 3,10: 4$, and $10: 5$. The above suspension was dispersed into $50 \mathrm{~mL}$ liquid paraffin, and then 5 drops of span 80 as emulsifier was added to the mixture. The mixture was stirred for $20 \mathrm{~min}$ to form water-in-oil (w/o) dispersion. Cross-linking reaction is composed of two steps.

Protection of $\mathrm{NH}_{2}$ Groups of Chitosan. $20 \mathrm{~mL}$ formaldehyde was dropped into the above mixture slowly and the $\mathrm{pH}$ of the mixture is adjusted to 10 . Then mixture was reacted at $60^{\circ} \mathrm{C}$ for $15 \mathrm{~min}$ in Microwave Synthesis Workstation (Microwave Synthesis Workstation MAS-I: Sineo Microwave Chemistry Technology Co., Ltd.) to cross-link the chitosan. Then the microspheres were collected by removing the liquid paraffin and water from the mixture.

Cross-Linking of Chitosan by Epichlorohydrin. $0.5 \mathrm{~g}$ epichlorohydrin was dissolved in $50 \mathrm{~mL}$ ethanol. $\mathrm{pH}$ of this solution was adjusted to 10 by $0.1 \mathrm{~mol} / \mathrm{L} \mathrm{NaOH}$ solution. Microsphere was added to the above epichlorohydrin solution and crosslinked by epichlorohydrin in Microwave Synthesis Workstation for $40 \mathrm{~min}$ at $80^{\circ} \mathrm{C}$. The cross-linked microsphere was washed by distilled water for three times and dipped in $0.5 \mathrm{~mol} / \mathrm{L} \mathrm{HCl}$ solution to get rid of the Schiff base formed by formaldehyde. The microsphere was washed with distilled water to a neutral $\mathrm{pH}$. Composite particles with chitosan/activated carbon mass ratios of $10: 1,10: 2,10: 3$, $10: 4$, and $10: 5$ were labeled as CA1, CA2, CA3, CA4, and CA5, respectively.

2.3. Chitosan Microspheres Preparation. Chitosan microspheres were prepared as the above procedure but no activated carbon was added. Chitosan microsphere was coded as CA0.

2.4. Characterization of the Composite Microsphere. The morphology of composite microspheres was observed by scan electronic microscope (Hitachi SU8010 Scanning Electron Microscope). FTIR spectrum of microsphere was recorded by Nicolet IS10 Fourier Transform Infrared Spectrometer (Thermo Fisher Scientific Inc.). Sample was milled with $\mathrm{KBr}$ and pressed to transparent pellet and then detected by FTIR. TGA (STA 409 PC Luxx NETZSCH) was performed by heating samples to $700^{\circ} \mathrm{C}$ at $5^{\circ} \mathrm{C} / \mathrm{min}$ under a nitrogen flow.

\subsection{Adsorption Studies}

2.5.1. Effect of Dose of Activated Carbon on Adsorption Ability of Composite Microsphere. 0.5 g CA0, CA1, CA2, CA3, CA4, CA5, CE (CA4 without amino protection), and activated carbon powder (ACP) were put into $50 \mathrm{~mL} 37.57 \mathrm{mg} / \mathrm{L}$ methyl orange solution, respectively. After standing for $72 \mathrm{~h}$, the absorbance of the supernatant was measured using VARIAN Cary $50 \mathrm{UV}-\mathrm{Vis}$ spectrophotometer at $466 \mathrm{~nm}$. The absorbance capacity is calculated according to the following equation:

$$
Q=\frac{\left(C_{0}-C\right) V}{m} .
$$

In the equation, $C_{0}$ is the initial concentration of methyl orange solution, $C$ is the concentration after adsorption, $V$ is the volume of solution, $m$ is the weight of microspheres ( $\mathrm{g}$ ), and $\mathrm{Q}$ is mass of adsorbed methyl orange per gram of microsphere.

2.5.2. Adsorption Kinetics. $0.05 \mathrm{~g}$ CA4 was immersed into $100 \mathrm{~mL} 30 \mathrm{mg} / \mathrm{L}$ methyl orange solution at $25^{\circ} \mathrm{C}$. At desired time intervals, $0.5 \mathrm{~mL}$ of dyes solution was taken out to detect the concentration of methyl orange using Vis spectrophotometer (VARIAN Cary 50) at wavelength of $466 \mathrm{~nm}$. Absorbance capacity is calculated using (1).

2.5.3. Adsorption Isotherm. $0.02 \mathrm{~g} \mathrm{CA} 4$ was put into $50 \mathrm{~mL}$ of $10 \mathrm{mg} / \mathrm{L}, 14 \mathrm{mg} / \mathrm{L}, 16.8 \mathrm{mg} / \mathrm{L}, 22.4 \mathrm{mg} / \mathrm{L}$, and $28 \mathrm{mg} / \mathrm{L}$ methyl orange solution, respectively. After standing for $72 \mathrm{~h}$ at $30^{\circ} \mathrm{C}$, $35^{\circ} \mathrm{C}$, and $40^{\circ} \mathrm{C}$, supernatant was taken out to measure the absorbance, and adsorption capacity was calculated.

2.5.4. Effect of the Temperature on Adsorption Ability. $0.02 \mathrm{~g}$ of CA 4 was placed in $50 \mathrm{~mL}(10 \mathrm{mg} / \mathrm{L})$ of methyl orange solution, respectively. The above mixture stood for $72 \mathrm{~h}$ while keeping the temperature at $25^{\circ} \mathrm{C}$. After adsorption, mixture was filtered and the residual concentration of the methyl orange was determined and the adsorption capacity of composite microsphere is calculated. Using the above procedure, adsorption capacity of CA2 at $25^{\circ} \mathrm{C}, 30^{\circ} \mathrm{C}, 35^{\circ} \mathrm{C}$, $40^{\circ} \mathrm{C}$, and $45^{\circ} \mathrm{C}$ was measured.

2.6. Regenerated Efficiency. CA1, CA2, CA3, CA4, and CA5 after adsorption were dipped into $0.5 \mathrm{~mol} / \mathrm{L} \mathrm{NaOH}$ solution to be regenerated. Then these composite microspheres were washed with distilled water to a neutral $\mathrm{pH}$ and dried in oven. These composite microspheres were recycled to adsorb methyl orange under the same adsorption conditions.

\section{Results and Discussion}

3.1. Composite Microsphere Preparation. Epichlorohydrin as cross-linker will react with $\mathrm{NH}_{2}$ groups or hydroxyl groups of chitosan which leads to reduction of amino groups [12]. However, amino groups are the main active sites of adsorption. So we need to protect the amino groups before cross-linking reaction. In this study, formaldehyde has been selected to protect the $\mathrm{NH}_{2}$ groups of chitosan. Firstly, formaldehyde 


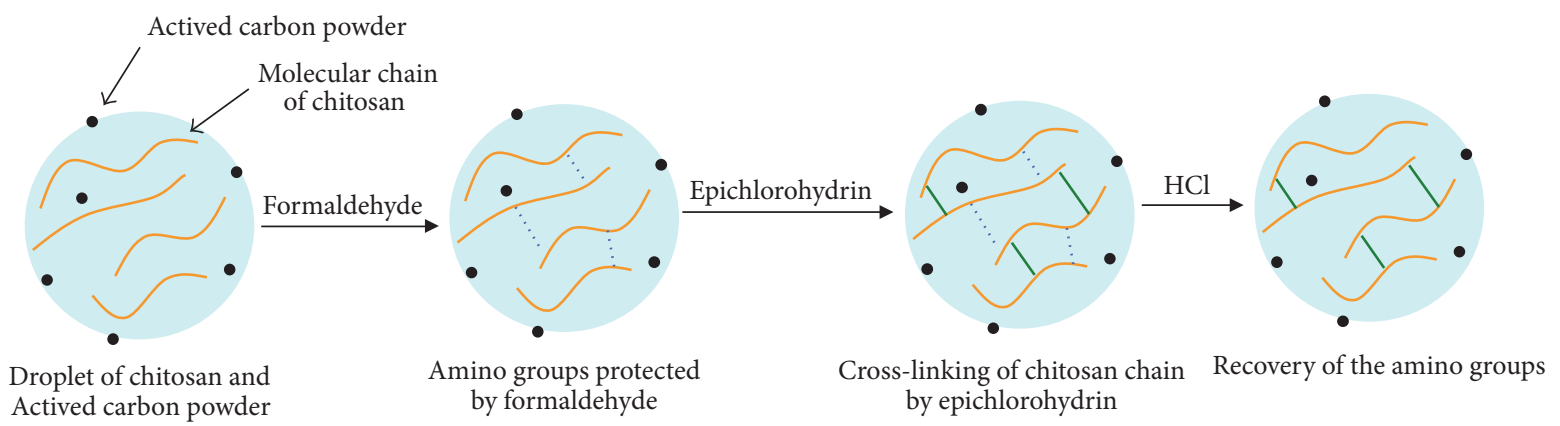

FIGURE 1: Schematic depiction of amino protection and cross-linking of chitosan-activated carbon composite microsphere.

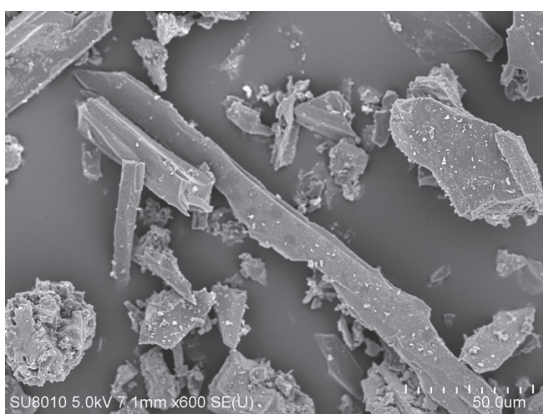

(a)

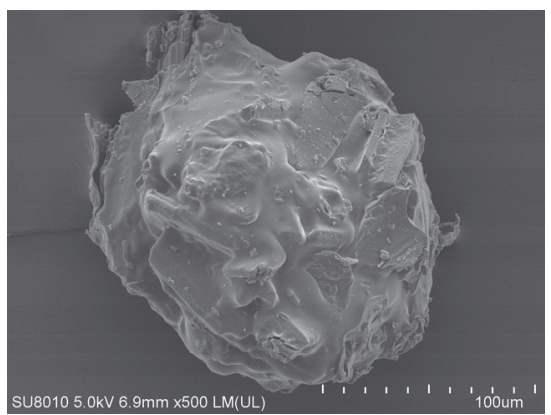

(d)

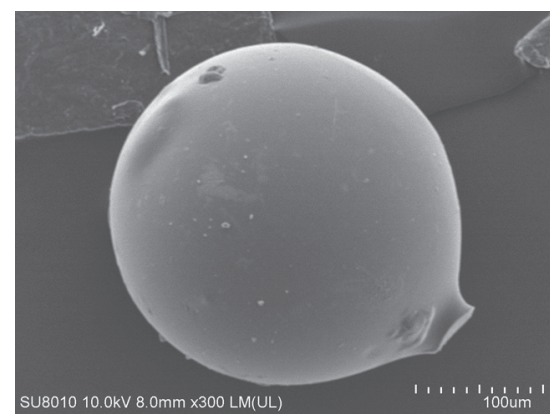

(b)

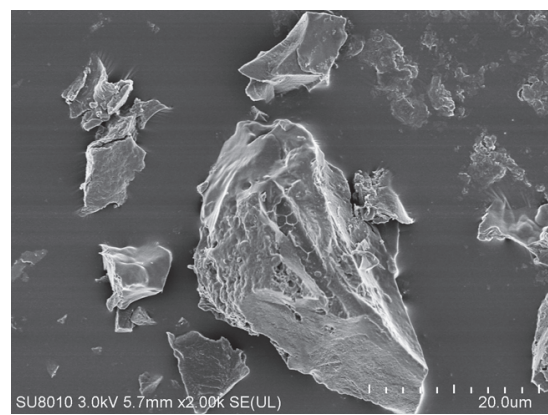

(e)

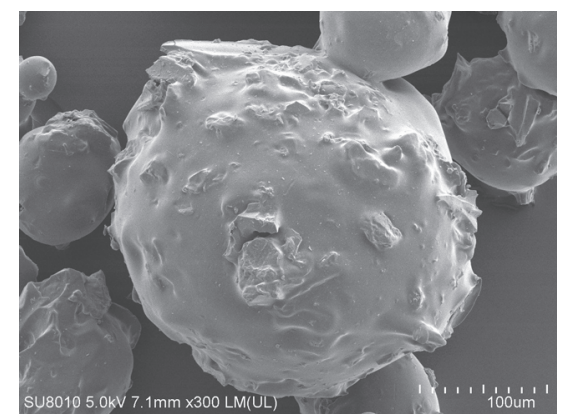

(c)

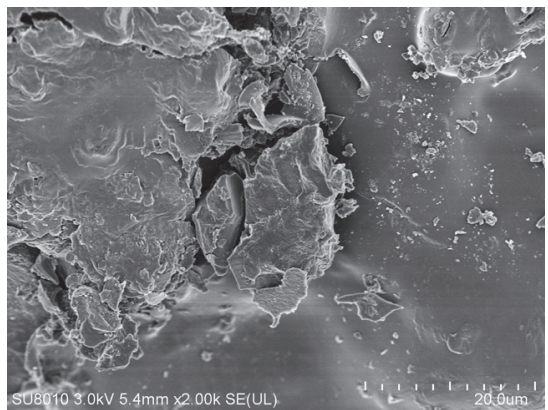

(f)

FIGURE 2: SEM photos: (a) activated carbon powder, (b) CA0, (c) CA1, (d) CA3, (e) surface of CA4, and (f) surface of CA5.

was reacted with $\mathrm{NH}_{2}$ groups of chitosan to form Schiff base. Secondly, epichlorohydrin was reacted with hydroxyl groups of chitosan to cross-link the chitosan molecules and then hard microsphere was formed after cross-linking. At last, Schiff base was removed by $0.5 \mathrm{~mol} / \mathrm{L} \mathrm{HCl}$ solution and $\mathrm{NH}_{2}$ groups of chitosan were recovered [17]. This process was illustrated in Figure 1. Using this method, chitosan composite microsphere with high amino group content was obtained.

Microwave irradiation has been widely used in various synthetic fields to assist reaction [18]. Compared to conventional heating method, microwave heating can shorten reaction time and lower energy consumption $[12,19]$. Microwaveassisted heating was highly efficient for assisting cross-linking reaction. The total reaction time was reduced to less than $1 \mathrm{~h}$ compared with the traditional heating method with more than 6 hours of reaction time [17].
3.2. Morphology and Structure of Composite Microsphere. SEM photos (Figure 2) show that the chitosan microspheres have diameters between 200 and $400 \mu \mathrm{m}$ and smooth surface. Composite microspheres also have diameters of 200-400 $\mu \mathrm{m}$ and activated carbon powder was distributed on the surface of microsphere. With the increase of the content of activated carbon, more activated carbon powders were observed on the surface of composite microsphere.

In CA4 FTIR spectrum (Figure 3), methylene vibrations $\left(2906 \mathrm{~cm}^{-1}\right.$ and $\left.2847 \mathrm{~cm}^{-1}\right)$ are enhanced obviously compared to chitosan. $\mathrm{CH}_{2}$ scissoring $\left(1422 \mathrm{~cm}^{-1}\right)$ is also enhanced indicating chitosan reacted with epichlorohydrin to form more $\mathrm{CH}_{2}$ groups. $1595 \mathrm{~cm}^{-1}$, corresponding to amide II groups (N-H bending vibrations coupled to $\mathrm{C}-\mathrm{N}$ stretching vibrations) [20], is not weak compared to amide II groups in chitosan spectrum, indicating that the $\mathrm{NH}_{2}$ groups 


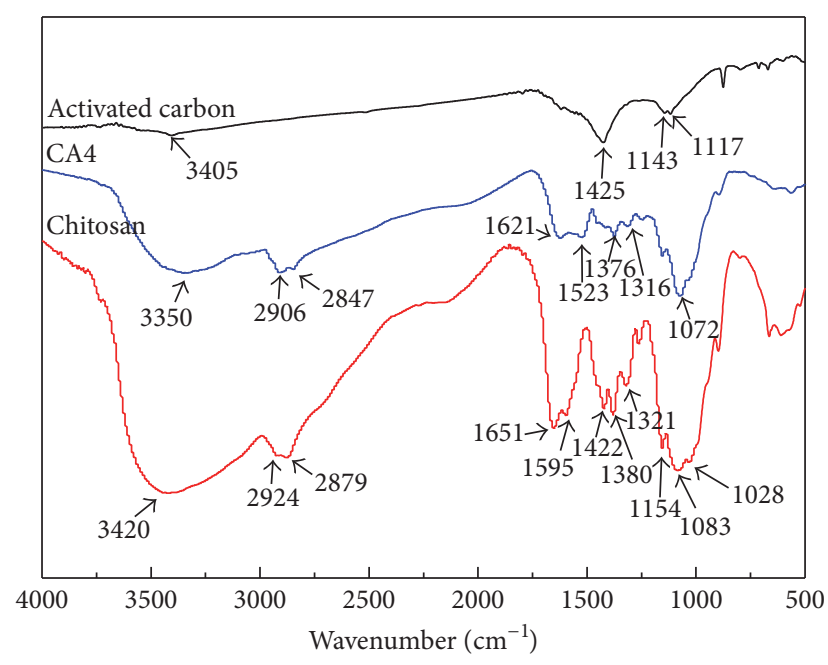

FIGURE 3: FTIR spectra of activated carbon, CA4, and chitosan.

are well protected. The absorption band of activated carbon was overlapped by CA4 spectrum.

TG curves for the activated carbon, chitosan, and composite microspheres (CA4) are presented in Figure 4. The weight loss of CA4 below $100^{\circ} \mathrm{C}$ was ascribed to the removal of water. Between $200^{\circ} \mathrm{C}$ and $350^{\circ} \mathrm{C}$, the rapid weight loss can be attributed to the decomposition of chitosan. Above $350^{\circ} \mathrm{C}$, the weight loss corresponds to the degradation of residual chitosan and activated carbon.

3.3. Adsorption Capacity. Adsorption capacity is shown in Figure 5. With the increasing of content of activated carbon, the adsorption capacity of composite microsphere increased until the mass ratio of chitosan to activated carbon reached $10: 4$, and then the adsorption capacity decreased. The largest absorption capacity is $35.4 \mathrm{mg} / \mathrm{g}$ and is larger than chitosan microsphere (CA0) which has adsorption capacity of $15.6 \mathrm{mg} / \mathrm{g}$. Composite microspheres have better adsorption capacities compared to chitosan microsphere $\mathrm{CA} 0$, which indicate that addition of activated carbon enhanced the adsorption of methyl orange. Activated carbon has been used as an adsorbent for removal of various dyes due to its porosity and large surface area. The increase of adsorption capacity of chitosan composite may be attributed to the porosity and larger surface area of the activated carbon. As shown in Figure 2, we can see more activated carbon powder distributed on the surface of composite microsphere when content of activated carbon increased.

When mass ratio exceeds $10: 4$, adsorption capacity decreased. The reason is that both the chitosan and activated carbon have the adsorption effect on methyl orange. Figure 5 shows that activated carbon powder (ACP) has larger adsorption capacity than chitosan microsphere (CA0). With the increase of activated carbon, more of activated carbon powder is embedded in the inner of microsphere instead of surface of microsphere which hinders the increase of adsorption capacity. Synergistic effect form by activated carbon and chitosan maybe is another reason to explain the

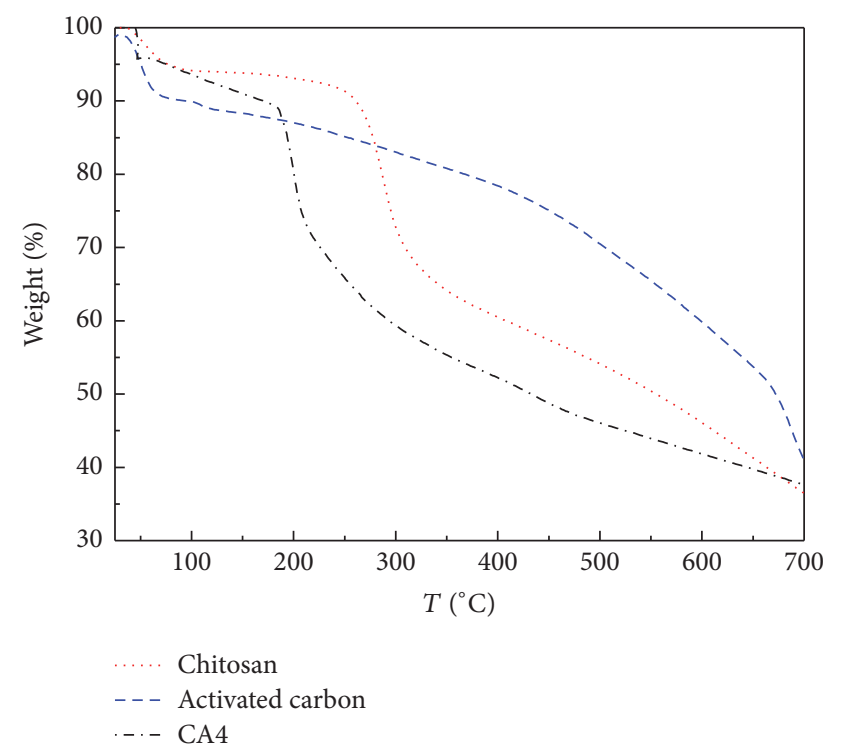

FIGURE 4: TG of chitosan, activated carbon, and CA4.

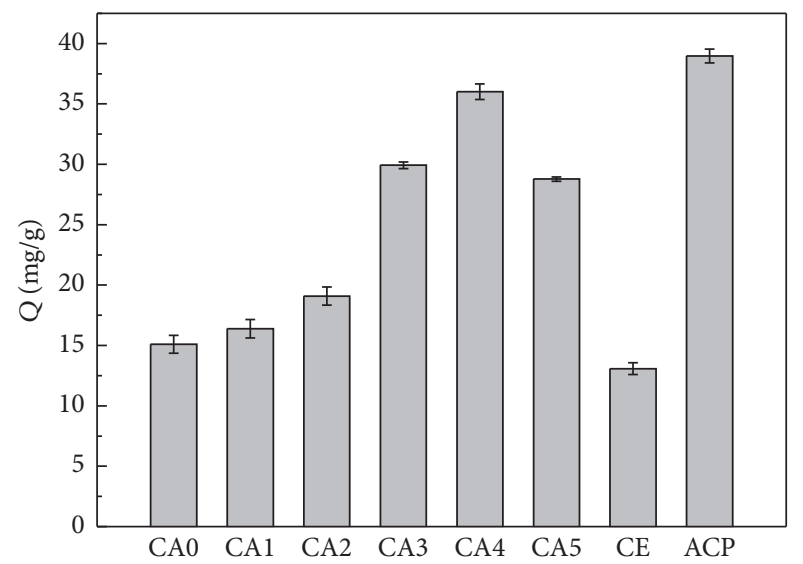

FIGURE 5: Adsorption capacities of CA0, CA1, CA2, CA3, CA4, CA5, $\mathrm{CE}$, and $\mathrm{ACP}$.

largest adsorption capacity of CA4. Compared with nonamino protection composite microsphere $(\mathrm{CE})$, protection of amino groups can effectively enhance the adsorption capacity.

Figure 6 shows the adsorption effect of CA4. The slight color of Figure 6(b) (after adsorption) reveals that the composite microspheres could effectively remove the methyl orange from water. The clear solution indicates that composite prevents the release of activated carbon powder into the water and prevents the second pollution of activated carbon powder to water.

3.4. Adsorption Kinetics. As shown in Figure 7, adsorption occurred quickly in $8 \mathrm{~h}$; after $72 \mathrm{~h}$, the adsorption reached equilibrium. Pseudo-first-order model [21] and pseudosecond-order model [22] were used to analyze the adsorption kinetic and the results are represented by Table 1. In Table 1, $Q_{\mathrm{eq}}(\mathrm{mg} / \mathrm{g})$ is the amount of dye adsorbed at equilibrium; $Q_{t}(\mathrm{mg} / \mathrm{g})$ is the amount of dye adsorbed at any time $t$ 


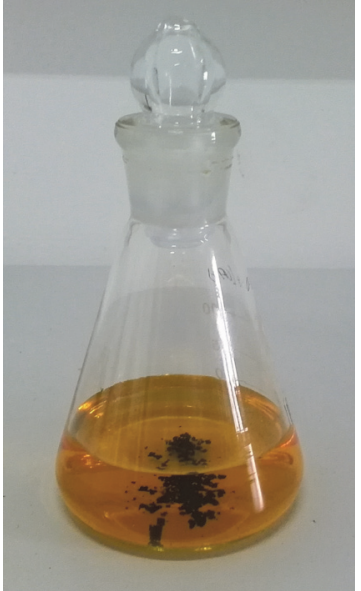

(a)

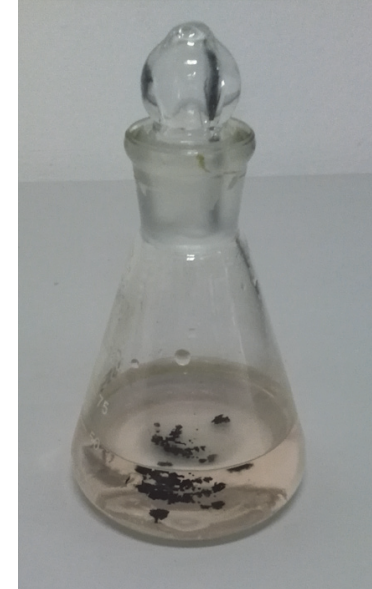

(b)

FIGURE 6: Adsorption effect of $0.02 \mathrm{~g}$ CA4 in $50 \mathrm{~mL} 10 \mathrm{mg} / \mathrm{L}$ methyl orange solution for $72 \mathrm{~h}$ ((a) before adsorption and (b) after adsorption).

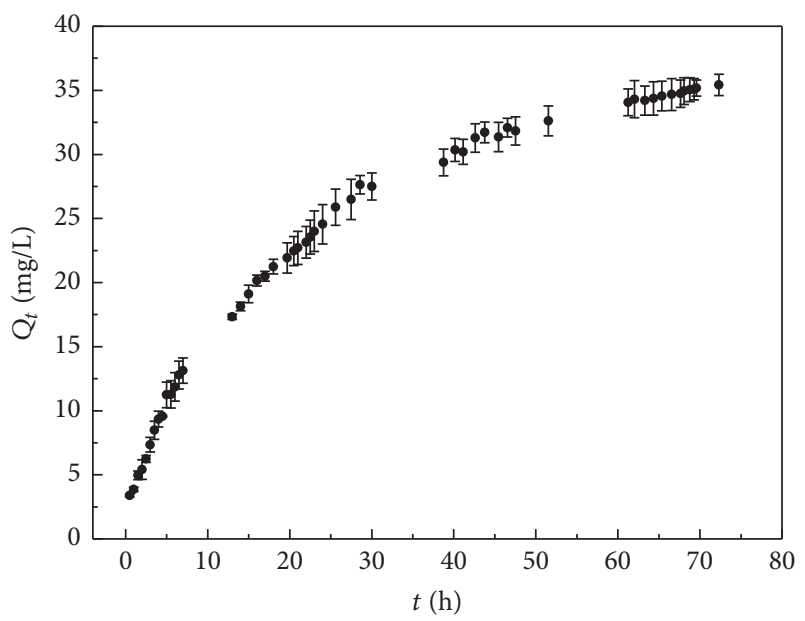

FIGURE 7: Adsorption capacity of CA4 for methyl orange with concentration of $30 \mathrm{mg} / \mathrm{L}$ at $25^{\circ} \mathrm{C}$ as a function of time.

(hour); $k_{1}$ and $k_{2}$ are the rate constant. Table 1 also shows the correlation coefficient $\left(R^{2}\right)$ of the linear form of pseudofirst-order model and pseudo-second-order model. 0.9912 of $R^{2}$ shows that the pseudo-second-order model is more suitable to describe the adsorption kinetic behavior of chitosan composite microsphere. This kinetic behavior was in agreement with chitosan/montmorillonite composite used for adsorbing Congo Red and chitosan/oil palm composite used for adsorbing Reactive Blue 19 [23, 24]. Kinetic behavior of pollutants adsorbed by adsorbent is usually described by pseudo-second-order equation [6].

3.5. Adsorption Isotherm. Adsorption isotherm of CA4 to methyl orange was shown as Figure 8. The adsorption capacity is increased with the increasing of concentration of methyl orange and decreased with the increasing of temperature.

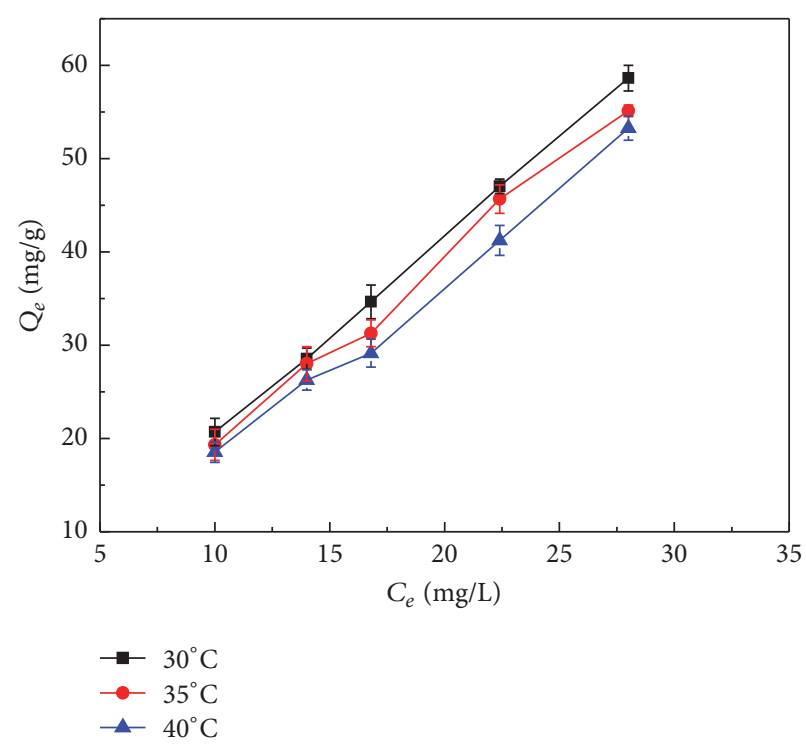

FIgURE 8: Adsorption isotherm of CA4 for methyl orange at $30^{\circ} \mathrm{C}$, $35^{\circ} \mathrm{C}$, and $40^{\circ} \mathrm{C}$.

Langmuir model [25] and Freundlich model [26] are used to analyze the adsorption isotherm. Langmuir model is used to describe monolayer homogeneous adsorption; the expression is

$$
\frac{1}{Q_{e}}=\frac{1}{Q_{\max }}+\frac{1}{Q_{\max } b} \frac{1}{C_{e}} .
$$

In the equation, $Q_{e}(\mathrm{mg} / \mathrm{g})$ is the amount of dye adsorbed at equilibrium; $b(\mathrm{~L} / \mathrm{mg})$ is a Langmuir constant with absorbance energy; $Q_{\max }(\mathrm{mg} / \mathrm{g})$ is the saturated adsorption capacity.

The expression of Freundlich model is shown in

$$
\ln Q_{e}=\left(\frac{1}{n}\right) \ln C_{e}+\ln K_{F} .
$$




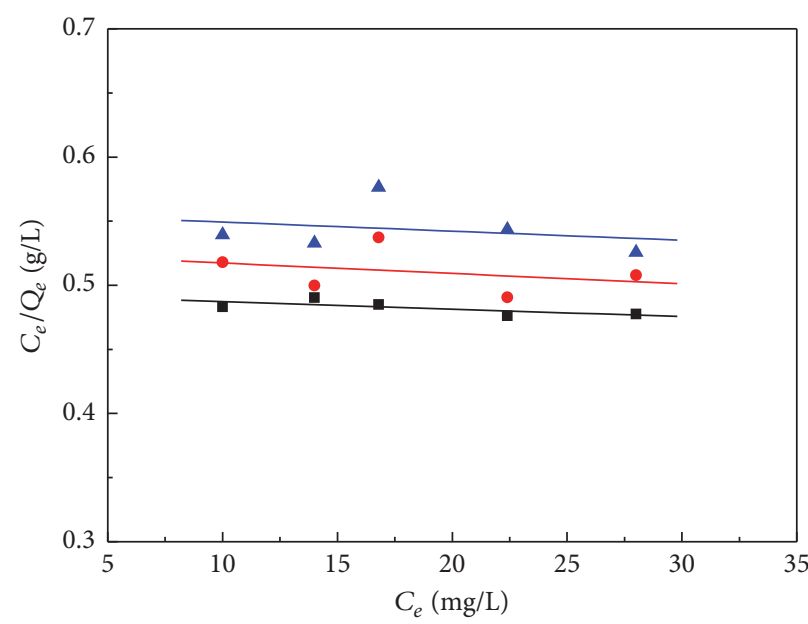

- $30^{\circ} \mathrm{C}$

- $35^{\circ} \mathrm{C}$

- $40^{\circ} \mathrm{C}$

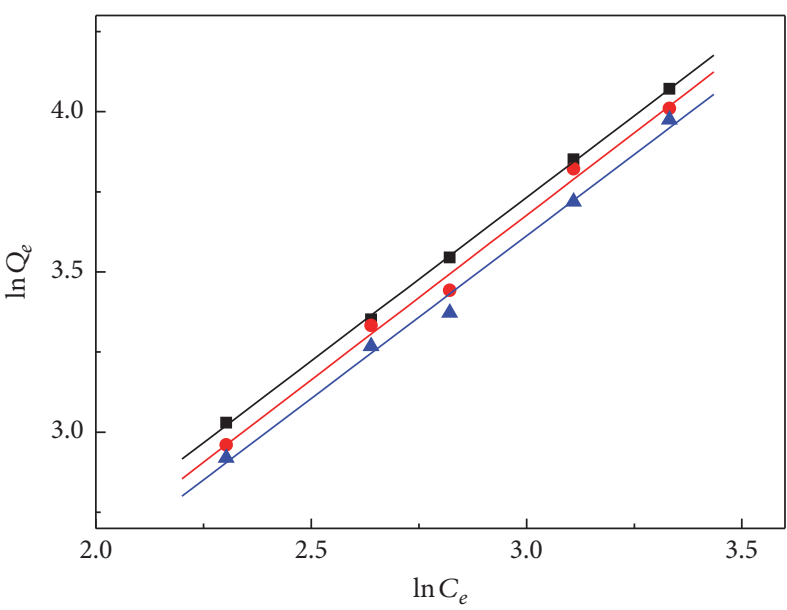

- $30^{\circ} \mathrm{C}$

- $35^{\circ} \mathrm{C}$

- $40^{\circ} \mathrm{C}$

(a)

(b)

Figure 9: Fitting curve of Langmuir model (a) and Freundlich model (b) of CA4.

TABLE 1: Kinetic models and parameters of CA4.

\begin{tabular}{lcccc}
\hline Kinetic model & Equation & Plot & Rate constant & Correlation coefficient \\
\hline Pseudo-first-order & $\log \left(Q_{\mathrm{eq}}-Q_{t}\right)=\log Q_{\mathrm{eq}}-k_{1} t$ & $\log \left(Q_{\mathrm{eq}}-Q_{t}\right)$ versus $t$ & 0.02547 & 0.9608 \\
Pseudo-second-order & $\frac{t}{Q_{t}}=\frac{1}{k_{2} Q_{\mathrm{eq}}^{2}}+\frac{1}{Q_{\mathrm{eq}}} t$ & $\frac{t}{Q_{t}}$ versus $t$ & 0.02364 & 0.9912 \\
\hline
\end{tabular}

TABLE 2: Isotherms parameters of composite microsphere (CA4).

\begin{tabular}{|c|c|c|c|c|c|c|}
\hline \multirow{2}{*}{$\mathrm{T} /{ }^{\circ} \mathrm{C}$} & \multicolumn{4}{|c|}{ Freundlich } & \multicolumn{2}{|l|}{ Langmuir } \\
\hline & Fitted equation & $K_{F}$ & $n$ & $R^{2}$ & Fitted equation & $R^{2}$ \\
\hline 30 & $\ln Q_{e}=1.0197 \times \ln C_{e}+0.9730$ & 1.9601 & 0.9807 & 0.9995 & $C_{e} / Q_{e}=-5.8223 \times 10^{-4} \times C_{e}+0.4930$ & 0.5148 \\
\hline 35 & $\ln Q_{e}=1.0273 \times \ln C_{e}+0.5949$ & 1.8128 & 0.9734 & 0.9936 & $C_{e} / Q_{e}=-8.0969 \times 10^{-4} \times C_{e}+0.5254$ & 0.1014 \\
\hline 40 & $\ln Q_{e}=1.0148 \times \ln C_{e}+0.5683$ & 1.7653 & 0.9854 & 0.9927 & $C_{e} / Q_{e}=-7.1214 \times 10^{-4} \times C_{e}+0.5565$ & 0.0665 \\
\hline
\end{tabular}

In (3), $K_{F}(\mathrm{mg} / \mathrm{g})$ is the Freundlich constant, related to adsorption capacity, and $1 / n$ is factor of heterogeneous phase, related to adsorption strength.

The fitted curve is shown in Figure 9 and the fitting results are shown in Table 2. As shown in Table 2, the adsorptive behaviors on composite microsphere could be better represented by the Freundlich model in the concentration range studied (correlation coefficient, $R^{2}>0.99$ ). This indicated that the methyl orange was adsorbed on the microsphere as a multilayer adsorption. The Freundlich model deals with adsorption on heterogeneous surfaces, which accord with the chitosan-activated carbon complex surface shown as Figures 2(c) and 2(d).

3.6. Effect of Temperature on Adsorption Capacity. From Figure 10, we can see that the adsorption capacity of CA4 has the largest value of $21.96 \mathrm{mg} / \mathrm{g}$ at $30^{\circ} \mathrm{C}$ in methyl orange

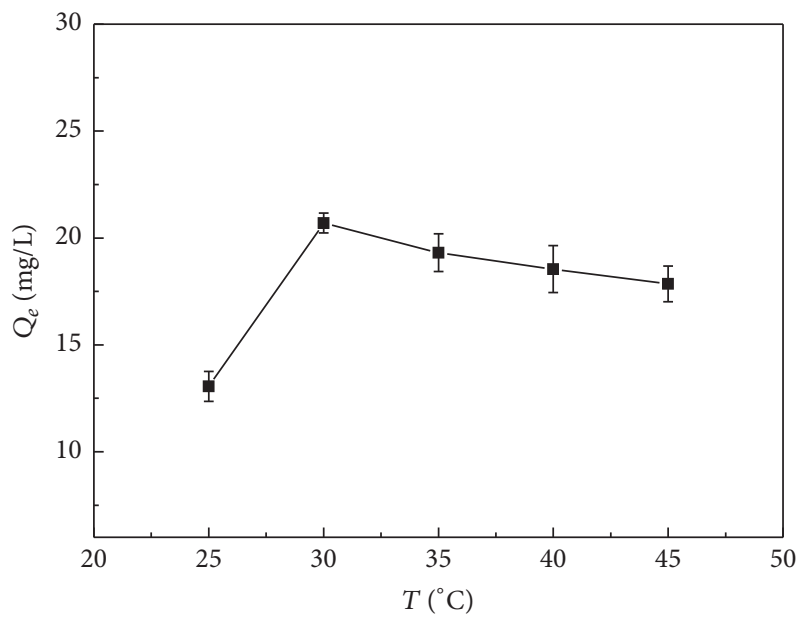

FIGURE 10: Effect of adsorption temperature on adsorption capacity of CA4 in $10 \mathrm{mg} / \mathrm{L}$ methyl orange solution. 
TABLE 3: Recovery of adsorption capacity of composite microspheres after adsorption.

\begin{tabular}{lccc}
\hline \multicolumn{2}{l}{ Sample Second adsorption } & Third adsorption & Fourth adsorption \\
\hline CA1 & $97.25 \%$ & $94.49 \%$ & $82.32 \%$ \\
CA2 & $94.63 \%$ & $88.57 \%$ & $54.22 \%$ \\
CA3 & $80.20 \%$ & $63.97 \%$ & $48.48 \%$ \\
CA4 & $60.67 \%$ & $49.65 \%$ & $38.34 \%$ \\
CA5 & $40.45 \%$ & $31.08 \%$ & $26.04 \%$ \\
\hline
\end{tabular}

solution. With the increasing of temperature, the adsorption capacity decreases.

3.7. Desorption and Reusability. Desorption and reusability results are shown in Table 3. After three cycles of adsorptiondesorption, adsorption capacity of CA1 remained $94.49 \%$ of initial adsorption capacity at the end of the third cycles. These results indicated that the composite can be regenerated easily and withstand the adsorption ability. The composite microspheres with high content of activated carbon are hard to regenerate because of the hard regeneration of activated carbon.

\section{Conclusions}

Chitosan composite microspheres were successfully prepared using emulsion cross-linking method under microwave irradiation. Results of SEM, FTIR, and TG indicated that complex of chitosan and activated carbon is successful. Composite microsphere has larger adsorption capacities than chitosan. The largest adsorption capacity is $35.4 \mathrm{mg} / \mathrm{g}$ for methyl orange (mass ratio of chitosan to activated carbon is $10: 4$ ). Kinetic studies showed that the adsorption followed a pseudosecond-order model. The adsorption is dependent on temperature and the best adsorption occurred at $30^{\circ} \mathrm{C}$. Isotherm studied show that the isotherm adsorption equilibrium is better described by Freundlich isotherm. After reused for three cycles, adsorption capacity remained $94.49 \%$. Therefore, the composite microsphere is promising for application in the removal of dyes from industrial wastewater.

\section{Competing Interests}

The authors declare that they have no competing interests.

\section{Acknowledgments}

The authors would like to thank the Scientific Research Foundation for Doctors of Jinling Institute of Technology (Grant no. jit-b-201415) and the Natural Science Foundation for Colleges and Universities of Jiangsu Province (Grant no. $12 \mathrm{KJD} 150006)$ for the financial support of this research.

\section{References}

[1] G. R. Mahdavinia, H. Aghaie, H. Sheykhloie, M. T. Vardini, and H. Etemadi, "Synthesis of CarAlg/MMt nanocomposite hydrogels and adsorption of cationic crystal violet," Carbohydrate Polymers, vol. 98, no. 1, pp. 358-365, 2013.
[2] X.-F. Sun, B. Liu, Z. Jing, and H. Wang, "Preparation and adsorption property of xylan/poly(acrylic acid) magnetic nanocomposite hydrogel adsorbent," Carbohydrate Polymers, vol. 118, pp. 16-23, 2015.

[3] W. S. Wan Ngah, L. C. Teong, and M. A. K. M. Hanafiah, "Adsorption of dyes and heavy metal ions by chitosan composites: a review," Carbohydrate Polymers, vol. 83, no. 4, pp. 14461456, 2011.

[4] J. Labanda, J. Sabaté, and J. Llorens, "Modeling of the dynamic adsorption of an anionic dye through ion-exchange membrane adsorber," Journal of Membrane Science, vol. 340, no. 1-2, pp. 234-240, 2009.

[5] B. Shi, G. Li, D. Wang, C. Feng, and H. Tang, "Removal of direct dyes by coagulation: the performance of preformed polymeric aluminum species," Journal of Hazardous Materials, vol. 143, no. 1-2, pp. 567-574, 2007.

[6] X. Luo and L. Zhang, "High effective adsorption of organic dyes on magnetic cellulose beads entrapping activated carbon," Journal of Hazardous Materials, vol. 171, no. 1-3, pp. 340-347, 2009.

[7] Y. Shi, Z. Xue, X. Wang, L. Wang, and A. Wang, "Removal of methylene blue from aqueous solution by sorption on lignocellulose-g-poly(acrylic acid)/montmorillonite threedimensional cross-linked polymeric network hydrogels," Polymer Bulletin, vol. 70, no. 4, pp. 1163-1179, 2013.

[8] L. Wang, J. Zhang, and A. Wang, "Fast removal of methylene blue from aqueous solution by adsorption onto chitosan-g-poly (acrylic acid)/attapulgite composite," Desalination, vol. 266, no. 1-3, pp. 33-39, 2011.

[9] H.-L. Cheng, Q.-H. Feng, C.-A. Liao, Y. Liu, D.-B. Wu, and Q.G. Wang, "Removal of methylene blue with hemicellulose/clay hybrid hydrogels," Chinese Journal of Polymer Science, vol. 34, no. 6, pp. 709-719, 2016.

[10] G. Crini and P.-M. Badot, "Application of chitosan, a natural aminopolysaccharide, for dye removal from aqueous solutions by adsorption processes using batch studies: a review of recent literature," Progress in Polymer Science, vol. 33, no. 4, pp. 399447, 2008.

[11] S. Babel and T. A. Kurniawan, "Low-cost adsorbents for heavy metals uptake from contaminated water: a review," Journal of Hazardous Materials, vol. 97, no. 1-3, pp. 219-243, 2003.

[12] H. Ge and X. Fan, "Adsorption of $\mathrm{Pb}^{2+}$ and $\mathrm{Cd}^{2+}$ onto a novel activated carbon-chitosan complex," Chemical Engineering \& Technology, vol. 34, no. 10, pp. 1745-1752, 2011.

[13] K. Azlan, W. N. W. Saime, and L. L. Ken, "Chitosan and chemically modified chitosan beads for acid dyes sorption," Journal of Environmental Sciences, vol. 21, no. 3, pp. 296-302, 2009.

[14] E. Guibal, "Interactions of metal ions with chitosan-based sorbents: a review," Separation and Purification Technology, vol. 38, no. 1, pp. 43-74, 2004.

[15] F.-C. Wu, R.-L. Tseng, and R.-S. Juang, "Enhanced abilities of highly swollen chitosan beads for color removal and tyrosinase immobilization," Journal of Hazardous Materials, vol. 81, no. 1-2, pp. 167-177, 2001.

[16] M.-S. Chiou, P.-Y. Ho, and H.-Y. Li, "Adsorption of anionic dyes in acid solutions using chemically cross-linked chitosan beads," Dyes and Pigments, vol. 60, no. 1, pp. 69-84, 2004.

[17] X. L. Yang, Z. Zhang, and Y. H. Zhu, "Preparation of crosslinked chitosan porous microspheres with high-level amidocyanogen and their adsorption for dyestuff," The Chinese Journal of Process Engineering, vol. 9, pp. 31-34, 2009. 
[18] Y. Guo, J. Zhou, Y. Song, and L. Zhang, "An efficient and environmentally friendly method for the synthesis of cellulose carbamate by microwave heating," Macromolecular Rapid Communications, vol. 30, no. 17, pp. 1504-1508, 2009.

[19] V. Singh, D. N. Tripathi, A. Tiwari, and R. Sanghi, "Microwave synthesized chitosan-graft-poly(methylmethacrylate): an efficient $\mathrm{Zn}^{2+}$ ion binder," Carbohydrate Polymers, vol. 65, no. 1, pp. 35-41, 2006.

[20] C. T. Tsao, C. H. Chang, Y. Y. Lin et al., "Antibacterial activity and biocompatibility of a chitosan- $\gamma$-poly(glutamic acid) polyelectrolyte complex hydrogel," Carbohydrate Research, vol. 345, no. 12, pp. 1774-1780, 2010.

[21] S. Lagergren, "About the theory of so-called adsorption of soluble substances," Kungliga Svenska Vetenskapsakademiens Handlingar, vol. 24, p. 38, 1898.

[22] Y. S. Ho and G. McKay, "Sorption of dye from aqueous solution by peat," Chemical Engineering Journal, vol. 70, no. 2, pp. 115124, 1998.

[23] L. Wang and A. Wang, "Adsorption characteristics of Congo Red onto the chitosan/montmorillonite nanocomposite," Journal of Hazardous Materials, vol. 147, no. 3, pp. 979-985, 2007.

[24] M. Hasan, A. L. Ahmad, and B. H. Hameed, "Adsorption of reactive dye onto cross-linked chitosan/oil palm ash composite beads," Chemical Engineering Journal, vol. 136, no. 2-3, pp. 164172, 2008.

[25] I. Langmuir, "The adsorption of gases on plane surfaces of glass, mica and platinum," Journal of the American Chemical Society, vol. 40, no. 9, pp. 1361-1403, 1918.

[26] H. M. F. Freundlich, "Über die adsorption in lösungen," Zeitschrift für Physikalische Chemie, vol. 57, p. 470, 1906. 

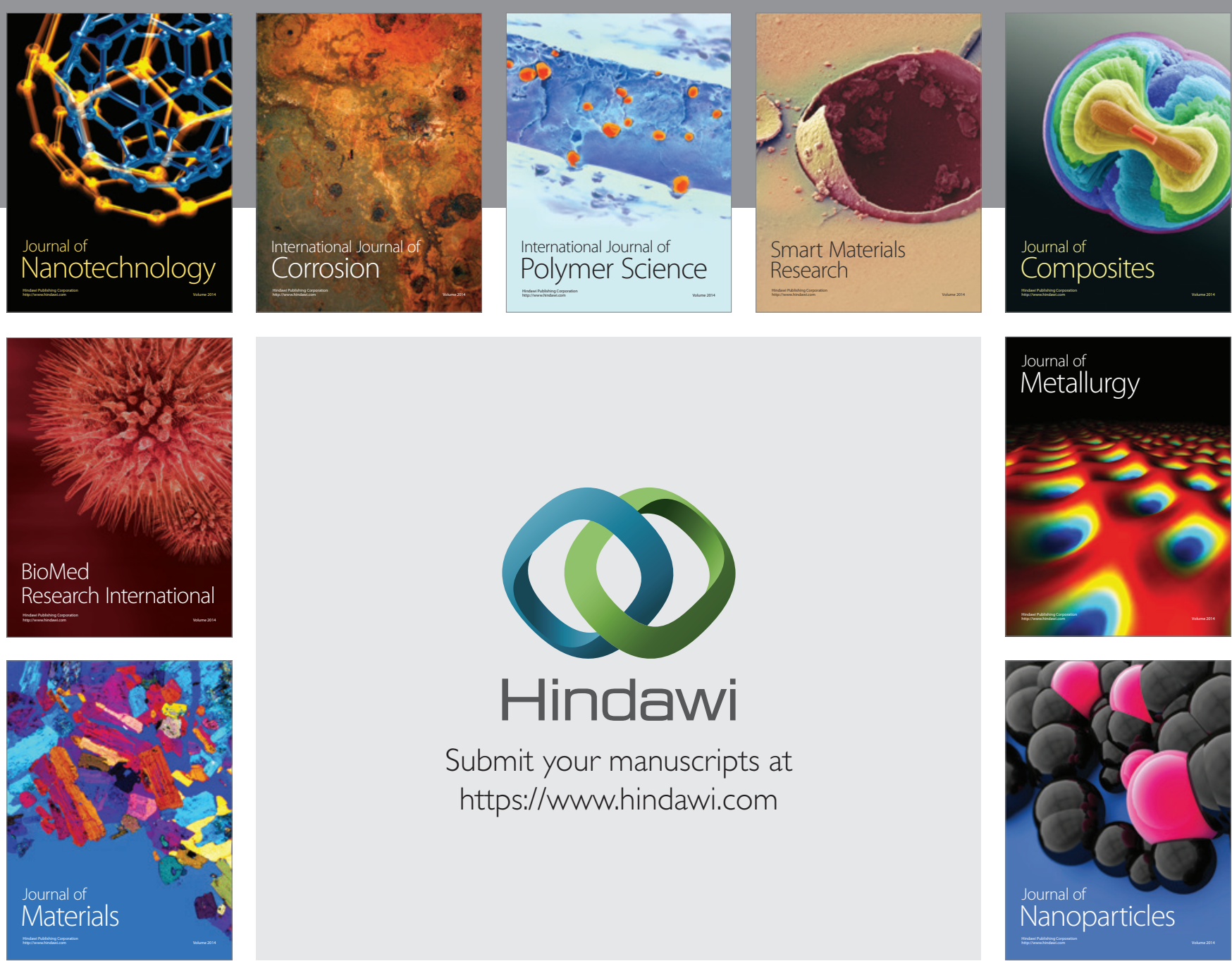

\section{Hindawi}

Submit your manuscripts at

https://www.hindawi.com

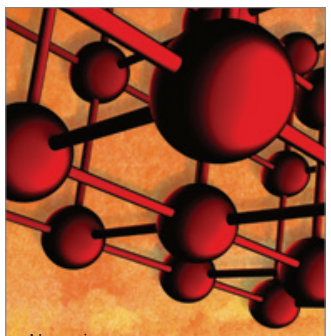

Materials Science and Engineering
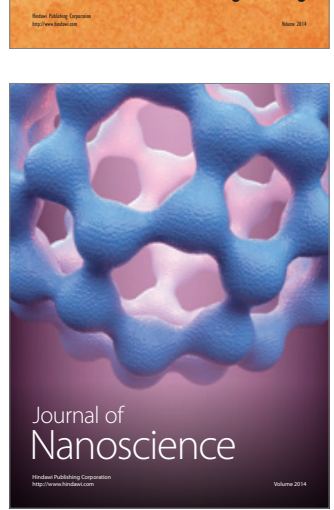
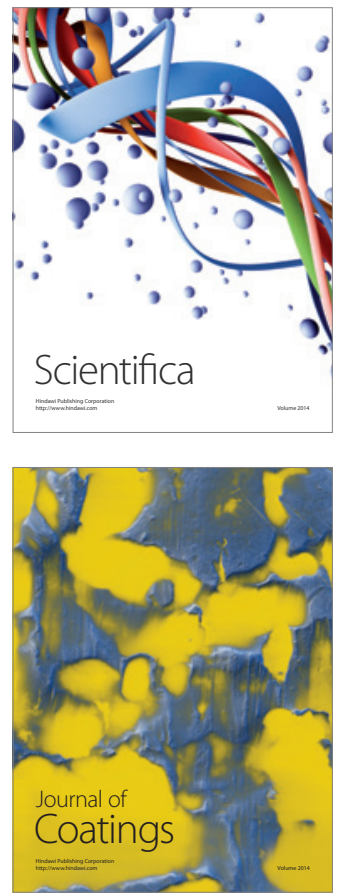
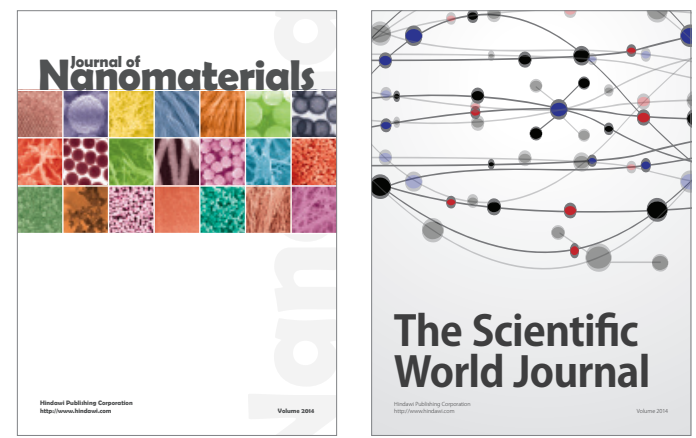

The Scientific World Journal
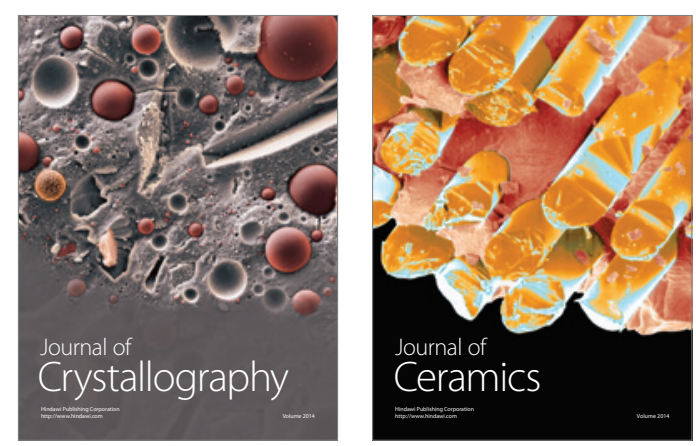
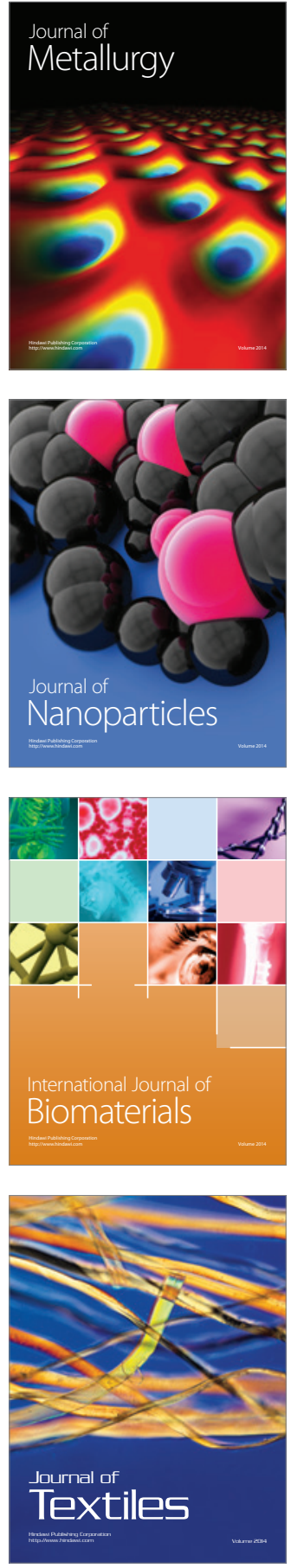